Mini Review

\title{
Recent Development of Wearable Electrochemical Sensors for Sweat Analysis
}

\author{
Hanqiao $\mathrm{Li}^{1}$, Yanfen Xiao ${ }^{1}$, Li $\mathrm{Jin}^{2,3, *}$ \\ ${ }^{1}$ Basic Science Department, Wuchang Shouyi University, Wuhan 430064, China \\ ${ }^{2}$ College of Health Science, Wuhan Sports University, Wuhan 430079, China \\ ${ }^{3}$ Hubei Exercise Training and Monitoring Key Laboratory, Wuhan Sports University, Wuhan 430079, \\ China \\ *E-mail: 1ijin@wcsy-uni.cn
}

doi: $10.20964 / 2020.12 .22$

Received: 15 August 2020 / Accepted: 16 September 2020 / Published: 31 October 2020

\begin{abstract}
Sweating during training and competition leads to a large amount of water and electrolyte loss, along with the excretion of lactic acid, urea, creatine, creatinine and other metabolites into sweat. Through sweat analysis, we can quickly understand the physical condition, metabolism and adaptability of a human body. This is of great practical significance in athlete selection, daily sports training and physical fitness recovery. In recent years, with the rapid development of flexible printing of electronic technology and the Internet of Things, all kinds of miniaturized wearable devices that can obtain real-time data information have been increasingly developed. This short review summarizes the recent development of wearable devices in sweat analysis technology.
\end{abstract}

Keywords: Wearable device; Electrochemistry; Sweat analysis; Athlete; Sports training; Biosensor

\section{FULL TEXT}

(C) 2020 The Authors. Published by ESG (www.electrochemsci.org). This article is an open access article distributed under the terms and conditions of the Creative Commons Attribution license (http://creativecommons.org/licenses/by/4.0/). 